\title{
Supporting information: Sphalerite oxidation in seawater with covellite: implications for seafloor massive sulfide deposits and mine waste
}

Amy Gartman*, Samantha P. Whisman, and James R. Hein

Two pages containing two supporting figures, and one table attached as an excel file
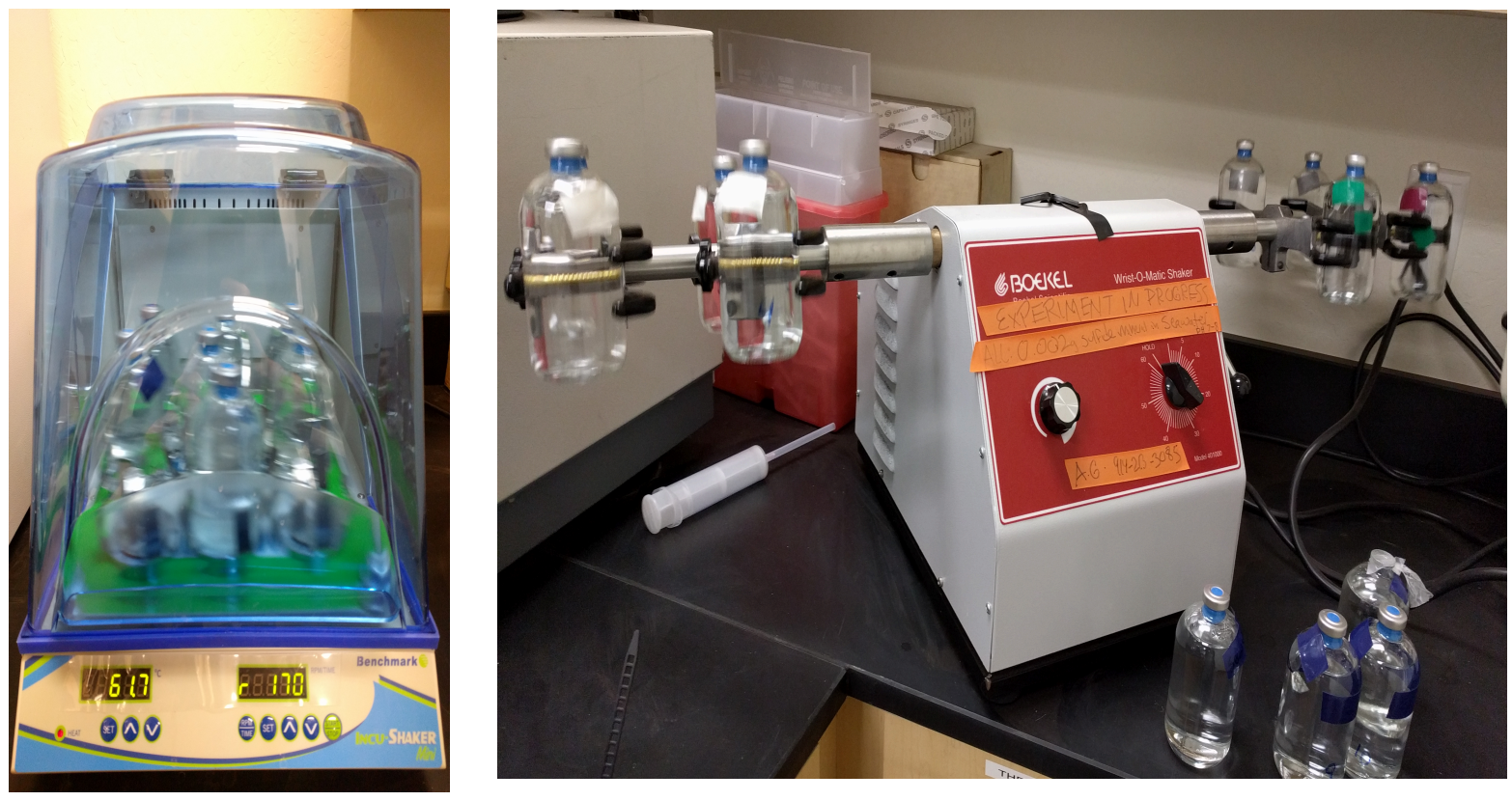

Figure S1: Shakers used in this study 


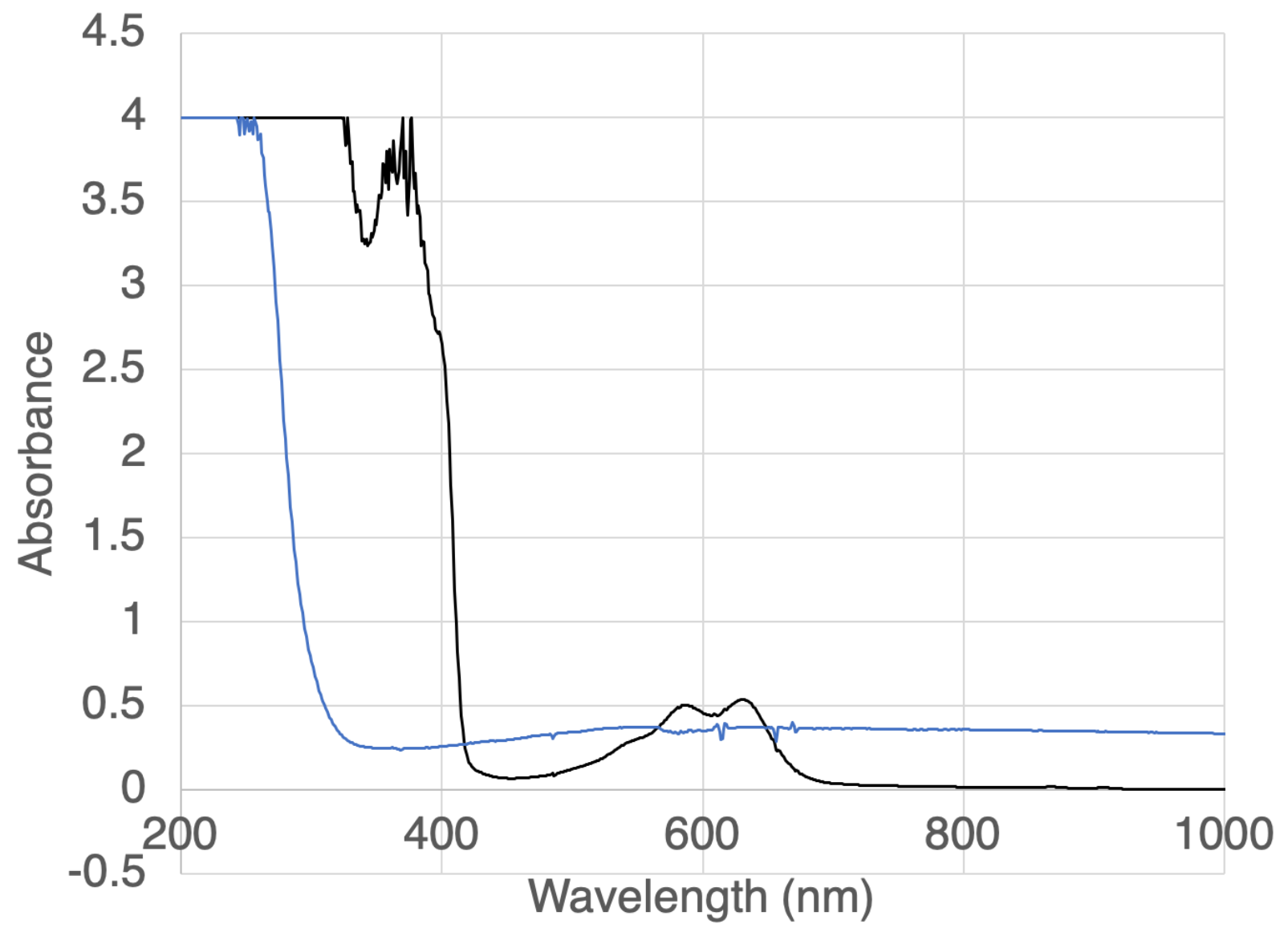

Figure S2: Absorbance of heated shaker cover (black, used for used for $42^{\circ} \mathrm{C}$ and $62^{\circ} \mathrm{C}$ trials) and glass bottles used with the wrist action shaker (used for $22^{\circ} \mathrm{C}$ ) trials. 